\title{
Investigation into Rain Attenuation Prediction Models at Locations in Lagos Using Remote Sensing
}

\author{
*Olufunke Darley, Abayomi I.O. Yussuff and Adetokunbo A. Adenowo \\ Department of Electronic and Computer Engineering, Lagos State University, Epe Campus, Nigeria \\ \{funke_darleyl adetokyom\}@yahoo.com l abayomi.yussuff@lasu.edu.ng \\ Received: 26-APR-2021; Reviewed: 22-MAY-2021; Accepted: 14-JUN-2021 \\ http://dx.doi.org/10.46792/fuoyejet.v6i2.626
}

\begin{abstract}
This paper investigated the performances of some rain attenuation prediction models at some GSM network locations in Lagos, Nigeria, using remote sensing at Ku band. Remote sensing is a collection and interpretation of information about an object without physical contact with the object being measured. Three popular terrestrial prediction models were considered in this work. These are ITU-R P.530-17, Lin and Silva Mello Models. Ten years (2010-2019) annual rainfall data with hourly integration time were sourced from the Nigerian Meteorological Agency (NIMET) and link budgets for three microwave links (Tarzan Yard, Kofo Abayomi and GLO Shop) in Victoria Island at $18 \mathrm{GHz}$ were obtained from Global Communications Limited (GLO), Nigeria. Data analysis and comparison of the microwave links rainfall estimates were carried out to identify the most suitable of the three models at the selected locations of interest. Measurement data obtained from both NIMET and GLO were used to validate the predicted attenuation data from the three selected models. The ITU-R P.530-17 prediction model overestimated the measurement at Tarzan Yard; closely followed by Silva Mello, while Lin underestimated the measured data. Again, at Kofo Abayomi station, the ITU-R model overestimated the measurement, while both Silva Mello and Lin models underestimated the measurement. At the GLO Shop, the Silva Mello overestimated the measured value, while ITU-R and Lin underestimated the measurement. At $0.01 \%$ of time exceeded, NIMET measurement was higher (at $48.2 \mathrm{~dB}$ ) than that of Tarzan Yard, Kofo Abayomi and GLO shop (43.1, 46.3 and $37.0 \mathrm{~dB}$ respectively). These results will provide useful information in mitigating signal outages due to rain for mobile communication systems.
\end{abstract}

Keywords- Path attenuation, Prediction models, Rainfall rate, Terrestrial microwave links, Tropical region

\section{INTRODUCTION}

$\mathrm{R}$ ainfall is a natural occurrence and it varies based on location and time/season; from tropical areas with heavy rainfall to desert areas with extremely sparse rainfall. Remote sensing was defined by Barret (1983) as the science of observation from a distance. It is the collection of information relating to objects without being in physical contact with them; with data acquisition implemented by gathering electromagnetic (EM) radiation that emanates from targets of interest (Shaw \& Burke, 2003; Teeuw et al., 2005; Ali, 2010; Weng, 2013).

Measurement of rainfall can be done remotely through weather radars and satellites or on-site using rain gauges and hydrometers. Remote measurements have constraints such as site accessibility which hampers readings due to obstructions from local topography, changing nature of rainfall over time, low spatiotemporal resolution of radar, and radar calibration errors (Uijlenhoet et al, 2003). Others include inadequate, old and degrading installed instruments/measuring devices (Doumounia et al., 2014), especially in developing countries. These challenges cause discrepancies between rainfall measurements made through remote sensors and on-site devices. While the latter is most suitable for near surface measurements, the former is used for sensing precipitation at much higher altitudes. Therefore, to obtain a more precise rainfall measurement, data from both methods are used.

\section{${ }^{*}$ Corresponding Author}

Section B- ELECTRICAL/COMPUTER ENGINEERING \& COMPUTING SCIENCES Can be cited as:

Darley O., Yussuff A.I.O. and Adenowo A.A. (2021): Investigation into Rain Attenuation Prediction Models at Locations in Lagos Using Remote Sensing, FUOYE Journal of Engineering and Technology (FUOYEJET), 6(2), 19-24. http://dx.doi.org/10.46792/fuoyejet.v6i2.626
The need for a method that bridge the gap and produce accurate measurements led to the use of microwave (MW) links of cellular communication networks. This idea was first proposed by Atlas and Ulbrich (1977), who noted that the ability of rain to adversely affect transmitted MW signals provided an opportunistic method for rainfall measurement by using rain attenuation to estimate pathaveraged rainfall rate. MW antennas of commercial cellular networks are normally installed on dedicated towers or roof tops; typically located some meters above the ground and exchange EM signals between each other. These signals play a prominent role in the measurement of near-surface rainfall as they get attenuated by atmospheric elements such as hydrometeors (rain, fog, dust, hail, etc.) with rainfall having serious impact on radio wave propagation especially at MW frequencies.

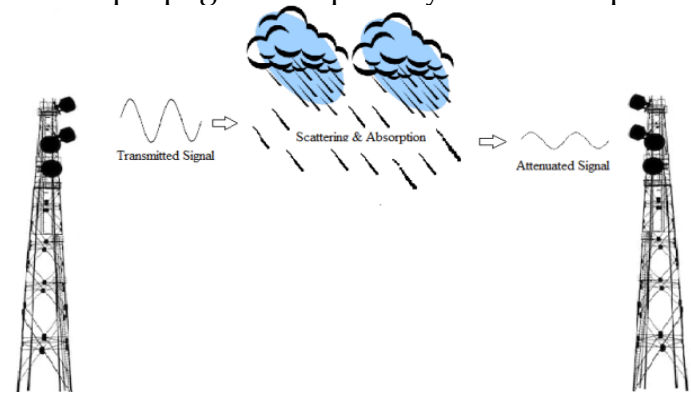

Fig.1: Attenuation of MW signals due to a rainfall event

Many researchers, including Mandeep et al, 2008; Siddique et al, 2011; Hossain, 2014; Shrestha and Choi, 2017a; Shrestha and Choi, 2017b; Kim and Byung, 2018; Akinyemi et al, 2018; Uijlenhoet et al, 2018 and Chwala and Kuntsman, 2019, have studied various aspects of rainfall estimation via signal attenuation on MW links. Some of these include rain intensity, polarization, operating frequency and effective path length. 
The underlying principle of rain attenuation (or rain fade) is that at MW frequencies, signals along the MW links are attenuated because the wavelength of the signal and the size of raindrops are close in dimension; thus, resulting in the scattering and absorption of signals by the atmosphere (See Figure 1).

Path attenuation, a consequence of heavy rainfall, can result in signals being indistinguishable from the noise signal of the receiver (Crane, 1996). The level of attenuation is determined by change of rainfall patterns in time and space. Therefore, signal losses can be converted into path-average rain rates; with every $\mathrm{MW}$ link acting as a path-average rain gauge. These links can provide rainfall measurements closer to ground level as an alternative to rain gauge measurements especially in areas where limited gauges are in existence. This can be a source of additional data in regions with inadequate rainfall data and can increase the spatio-temporal resolution of rainfall as well as accuracy of obtained rainfall products (Chwala and Kuntsman, 2019).

The universal use of cellular devices has ensured the everexpanding frontiers of cellular communication networks, which as reported by Ericson (2019), gave the total number of mobile subscriptions worldwide to be around 8 billion, including 6.2 billion broadband subscriptions for mobile devices. Thus, the existence of a high concentration of MW links in urban areas has provided a means through which rainfall can be mapped using signal attenuation data from the numerous links. This is of particular importance in geographically remote areas or where ready accessibility is challenging, such that the concentration of traditional devices is low; thereby, hindering proper gathering and recording of rainfall data, especially in tropical and equatorial regions of the world.

Total attenuation along a link (Kim and Byung, 2018) is given by:

$$
\left.A_{\text {tot }}(t)=A_{\text {clear }}(t)+A_{\text {rain }}(t)+A_{\text {wa }}(t)\right)
$$

Where,

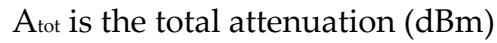

Aclear is the attenuation during clear skies preceding the rain event $(\mathrm{dBm})$

$A_{\text {rain }}$ is the attenuation due to rainfall $(\mathrm{dBm})$

$A_{w a}$ is the attenuation attributed to wet antenna $(\mathrm{dBm})$.

Overestimation of rain rates can occur owing to the influence of wet antenna on attenuation, and thus, necessary corrections must be taken to counter it (Leijnse et al, 2007). Rain rate is obtainable from total attenuation along a MW link with path length, L. This is made possible by the linear relationship between specific attenuation and rain rate, which is represented by (2) as follows:

$$
\gamma=k R^{\alpha}
$$

where:

$\gamma$ represents specific attenuation $(\mathrm{dB} / \mathrm{km})$ (attenuation per unit length) and varies with operating frequency, $\mathrm{f}(\mathrm{GHz})$ $R$ represents rain rate $(\mathrm{mm} / \mathrm{h})$ which varies with time and space. $k$ and $\alpha$ represents regression coefficients that vary with operating frequency, polarization characteristics, temperature, raindrop shape, distribution of raindrop size along link path and the path length.

Rain-induced attenuation prediction models are based on the product relationship between specific attenuation corresponding to the point rain rate measured at one end of the link, and the effective propagation path length (Crane, 1996). The effective path length in turn is a product of the path length and a correction/reduction factor, which is usually a fraction; thus, reducing the value of the path length. This factor seeks to account for the non-homogeneity of rainfall along the path of propagation. Attenuation models differ in terms of origin. While some focus on the correction factor, others centre on the extrapolation procedures used, all in an effort to present an accurate rain attenuation prediction.

Attenuation models have mostly been applied in temperate regions; with a lot fewer studies undertaken in tropical regions. Tropical regions usually have high intensities of rain with accompanying thunderstorms. (Busari and Fakolujo, 2021). The globally recognized ITU$\mathrm{R}$ model has been found to be more the suitable for temperate regions. When applied to tropical regions with its prevalent heavy rainfall characteristics, model was observed to either underestimate or overestimate the measured attenuation exceedances. Hence, there is need to present models with better fit that closely match the measurements via MW links, for the purpose of presenting reliable rain attenuation prediction models for use in tropical stations.

To investigate the suitability of some rain attenuation prediction models, rainfall data were obtained from the Nigerian Meteorological Agency (NIMET) while MW link data were obtained from Global Communications Limited (GLO). To start with, cumulative annual rainfall from NIMET and MW links data from GLO were used in estimating rainfall rates. Thereafter, data from three MW links were applied to three different attenuation prediction models (ITU-R, Lin and Silva Mello), and comparison made between predictions (estimates) and attenuation measurements (measured values).

Hence, this study attempts to show that with the correct choice of rain attenuation prediction model for terrestrial MW links, reliable path attenuation estimations can be obtained in the tropics; thus, providing useful information for mobile telecommunication systems designers with resultant improved network link availability $(99.9 \%, 99.99 \%$ and $99.999 \%$ availability for domestic, commercial and military applications, respectively).

\section{Methodology}

\subsection{RAINFALL DATA}

The climate of Lagos is tropical in nature and occurs with variable wet (or rainy) season from April to October and dry (or harmattan) season from November to March (Yussuff and Khamis, 2013). There is noticeable 
intermission in the rains during August with a short dry season often denoted as the "August break". Temperature and humidity remain relatively constant throughout the year with the mean monthly maximum temperatures steady at about $32^{\circ} \mathrm{C}$ and mean monthly minimum temperatures at about $22^{\circ} \mathrm{C}$ as observed by Yussuff and Khamis (2013). The process of data acquisition and analysis is presented in Figure 2.

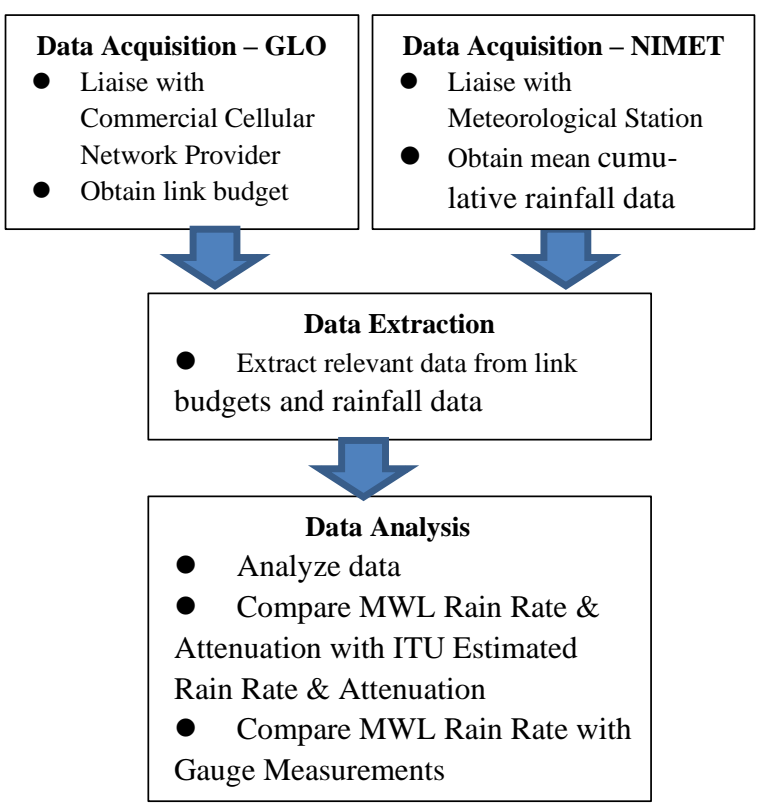

Fig. 2: Flow diagram for data acquisition and analysis

Annual rainfall cumulative distribution (CD) from 20102019 from rain gauge measurements were obtained from NIMET. One-minute integration time equivalent are derived from the hourly rain rate by applying the Chebil and Rahman (1999b) conversion technique as given in (3). This is because 1-minute rainfall data had been recognized as the best for attenuation prediction (Moupfouma et al, 1995; Chebil and Rahman, 1999a), but are typically not readily available in many developing countries, which include most of the tropical countries. Therefore, in the absence of 1-minute rainfall data, mean annual rainfall CD data or hourly rainfall data are used in the prediction of attenuation, as it was done in work presented by Chebil and Rahman (1999b). These are given in (3) and (4).

$$
R_{0.01}=a M^{b}
$$

where

$M$ is the mean annual rainfall cumulative

distribution $(\mathrm{mm}), \gamma_{R}$ is the specific attenuation $(\mathrm{dB} / \mathrm{km})$, $R_{0.01}$ is the rain rate exceeded $0.01 \%$ of time $(\mathrm{mm} / \mathrm{h})$, while $a$ and $b$ are regression coefficients.

$$
R_{1}(P)=R_{60}(P)\left[0.772 P^{-0.041}+1.141 \exp (-2.579 P)\right]
$$

where,

$R_{1}(P)$ is the rain rate for a given percentage of time $P$ with an integration time of 1 minute,

$R_{60}(P)$ is the rain rate for a given percentage of time $P$ with an integration time of 60 minutes, $P$ is the percentage of time. Measured rain rate was used for comparison with MW link rainfall rate estimates.

\subsection{MicrowaVe LinK DATA}

Three MW links having the same operating frequency of $18 \mathrm{GHz}$, and under the coverage Lagos Island weather station were considered. Namely: GLO Shop VI (Lat. $6^{\circ} 25^{\prime} \mathrm{N}$, Long. $3^{\circ} 25^{\prime} \mathrm{E}$ ), Kofo Abayomi (Lat. $6^{\circ} 26^{\prime} \mathrm{N}$, Long. $003^{\circ} 24^{\prime} 18^{\prime \prime} .02 \mathrm{E}$ ) and Tarzan Yard (Lat. 06 $26^{\prime} 12^{\prime \prime} .04 \mathrm{~N}$, Long. $\left.003^{\circ} 26^{\prime} 48^{\prime \prime} .26 \mathrm{E}\right)$.

Link budgets of these three links were obtained from GLO for January to December 2013. This is summarized in Table 1.

\begin{tabular}{cccccccc}
\multicolumn{6}{c}{ Table 1. Summary of link budgets for the three sites } \\
\hline $\begin{array}{c}\text { Link } \\
\text { Name }\end{array}$ & $\mathbf{P}$ & $\begin{array}{c}\mathbf{T x} \\
\mathbf{( d B )}\end{array}$ & $\begin{array}{c}\mathbf{R x} \\
\mathbf{( d B})\end{array}$ & $\begin{array}{c}\mathbf{P L} \\
\mathbf{( k m})\end{array}$ & $\begin{array}{c}\mathbf{A} \\
\mathbf{( d B})\end{array}$ & $\begin{array}{c}\mathbf{R R} \\
\mathbf{( m m} / \mathbf{h})\end{array}$ \\
\hline $\begin{array}{c}\text { GLO } \\
\text { Shop VI } \\
\text { Kofo }\end{array}$ & $\mathrm{V}$ & 18 & -35.07 & 1.10 & 47.93 & 358.25 \\
$\begin{array}{c}\text { Abayomi } \\
\text { Tarzan } \\
\text { Yard }\end{array}$ & $\mathrm{H}$ & 10 & -36.01 & 1.46 & 51.49 & 278.90 \\
\hline
\end{tabular}

where:

P - Polarization, V -Vertical, H - Horizontal,

Tx - Transmitting Power, Rx - Receiving Power, PL - Path Length, A - Attenuation, and RR - Rain rate.

Three attenuation prediction models were investigated as detailed in the subsequent subsections.

\subsubsection{ITU-R P. 530-17 Model}

ITU-R P. 530-17 rain attenuation prediction model concentrates on path reduction factor $(\mathrm{r})$ and attenuation $\left(A_{p}\right)$ exceeded at $p \%$ of time and is given as follows:

$$
A_{p}=A_{0.01}\left(C_{1} p^{-\left[C_{2}+C_{3} \log _{10} p\right]}\right)
$$

where

$A_{0.01}$ is attenuation exceeded at $0.01 \%$ of the time exceeded, which is given by:

$$
\begin{aligned}
& A_{0.01}=\gamma_{R} d_{e f f} \\
& \gamma_{R}=k R_{0.01}^{\alpha} \\
& d_{e f f}=r d \\
& r=\frac{1}{0.477\left(d^{0.633}\right) R_{0.01}^{0.073 \alpha} f^{0.123}-10.579[1-\exp (-0.024 d)]}
\end{aligned}
$$

$\gamma_{R}$ is the specific attenuation $(\mathrm{dB} / \mathrm{km})$

$d_{e f f}$ is the effective path length $(\mathrm{km})$

$d$ is the actual path length $(\mathrm{km})$

$r$ is the path reduction factor at $\mathrm{p} \%$

$R_{0.01}$ is the rain rate exceeded $0.01 \%$ of time $(\mathrm{mm} / \mathrm{h})$

$f$ is the operating frequency $(\mathrm{GHz})$

$k$ and $\alpha$ are regression coefficients, which are dependent on frequency, polarization and rain temperature.

$C_{1}, C_{2}$ and $C_{3}$ are frequency dependent coefficients. 


\subsubsection{Lin Model}

The Lin (Lin, 1997) model also focused on path reduction factor $(r)$ and attenuation, $A_{p}$, exceeded at $p \%$ of time. It is given by:

$$
\begin{aligned}
& A_{p}=k R_{p}^{\alpha} L r_{p} \\
& r_{p}=\frac{1}{1+\frac{L}{L\left(R_{P}\right)}} \\
& L\left(R_{P}\right)=\frac{2623}{R_{P}-6.2}
\end{aligned}
$$

where

$R_{p}$ is the point rain rate $(\mathrm{mm} / \mathrm{h})$

$L$ is the link path length $(\mathrm{km})$

$r_{p}$ is the reduction factor

$\mathrm{k}$ and $\alpha$ are regression coefficients, as stated before.

\subsubsection{Revised Silva Mello Model}

The Revised Silva Mello model (Mello and Pontes, 2012) is predicated on two elements. These are: path reduction factor $(r)$ and effective rain rate. Attenuation, $A_{p}$, exceeded at $p \%$ of time, which is given as:

$$
\begin{aligned}
& A_{p}=\gamma_{p} d_{e f f} \\
& \gamma_{p}=k R_{e f f}^{\alpha} \\
& d_{e f f}=\frac{d}{1+\frac{d}{d_{0}}} \\
& d_{0}=119 R^{-0.244} \\
& R_{e f f}=1.763 R^{0.753+0.197 / d}
\end{aligned}
$$

where

$\gamma_{p}$ is the specific attenuation $(\mathrm{dB} / \mathrm{km})$

Again, $d_{\text {eff }}$ is the effective path length

$R_{\text {eff }}$ is effective rain rate $(\mathrm{mm} / \mathrm{h})$

$R$ is the rain rate $(\mathrm{mm} / \mathrm{h})$

$d$ is the path length $(\mathrm{km})$

$d_{0}$ is the equivalent rainfall cell diameter $(\mathrm{km})$

Again, $k$ and $\alpha$ are regression coefficients, as previously declared.

\section{RESULTS AND Discussions}

Lagos falls within the $\mathrm{P}$ Region of ITU Rain Zone classification; with rainfall intensity of $145 \mathrm{~mm} / \mathrm{h}$ at $0.01 \%$ of time exceeded. For the three links under investigation, the adoption of ITU-R data introduces considerable errors between link rain rate values and ITU-R estimates (see Table 1).

Figure 3 shows specific attenuation due to polarization for measured and ITU-R estimates. Specific attenuation is derived from the product relationship (See (2)) between specific attenuation and rainfall rate. At $18 \mathrm{GHz}$, specific attenuation for measured and ITU-R estimates due to horizontal polarization are $28.24 \mathrm{~dB}$ and $15.42 \mathrm{~dB}$ respectively, and $19.83 \mathrm{~dB}$ and $11.32 \mathrm{~dB}$ respectively for vertical polarization. It was observed that horizontal polarization presented higher attenuation on the links than vertical polarization. This is partly because rain drops are scattered mostly along the horizontal axis and horizontally polarized waves tend to have more portion of it attenuated, while vertically polarized waves have a smaller portion of it impacted by rain.

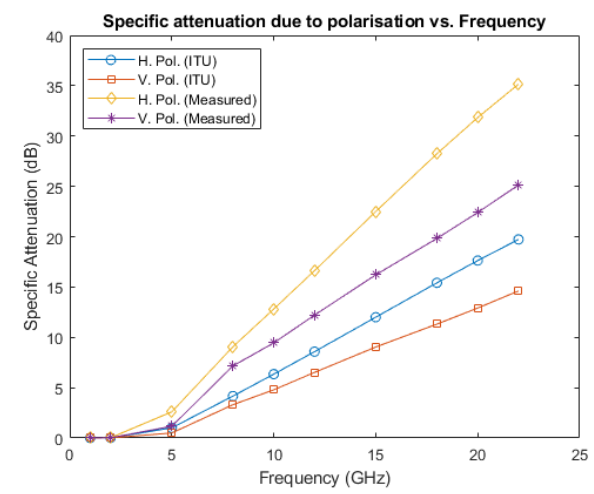

Fig. 3: Effect of polarization on specific attenuation for Lagos

Three attenuation prediction models were considered (ITU-R, Lin and Silva Mello). Locally sourced data from three links under investigation were tested with the models. For the Tarzan Yard Link (Figure 4), attenuation values for the models were similar for very short path lengths. As path length increased, there was a corresponding increase in path attenuation; with prediction models having diverging values. The Silva Mello model closely matched the measurement values; while Lin and ITU-R underestimated and overestimated the path attenuations, respectively.

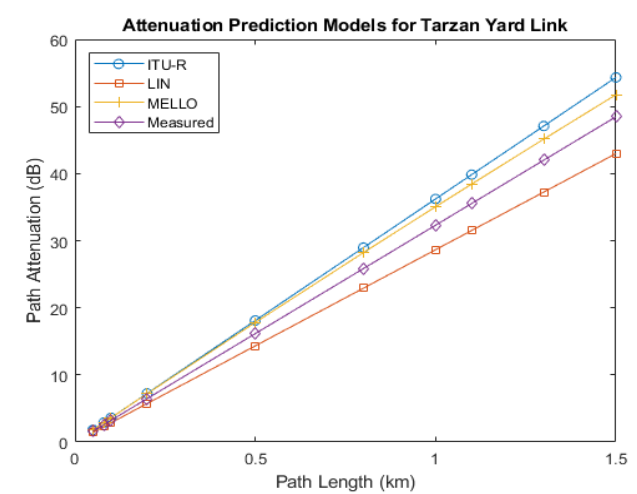

Fig. 4: Path attenuation vs. Path length for Tarzan Yard

For the Kofo Abayomi Link, as shown in Figure 5, path attenuation values are very close for short path lengths only. While both Silva Mello and Lin models underestimated measured values. The ITU-R model on the other hand overestimated the measurement.

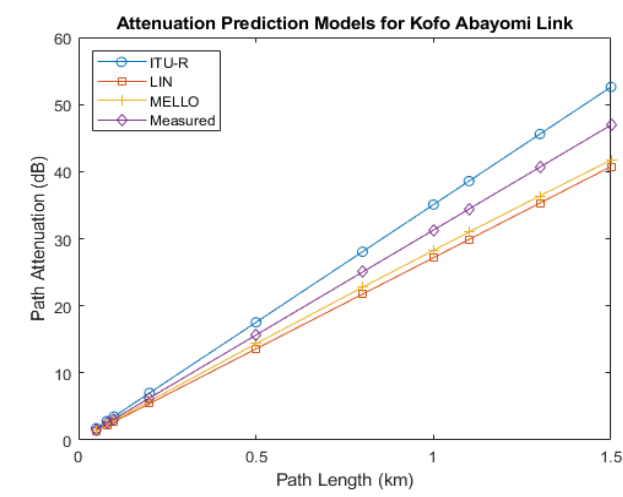

Fig. 5: Path attenuation vs. Path length for Kofo Abayomi 
Figure 6 shows the results of attenuation models when applied to the data obtained for GLO Shop, Victoria Island Link. It can be seen that of the three models, only the Silva Mello overestimated the measurement, while ITU-R and Lin underestimated the measured path attenuation values.

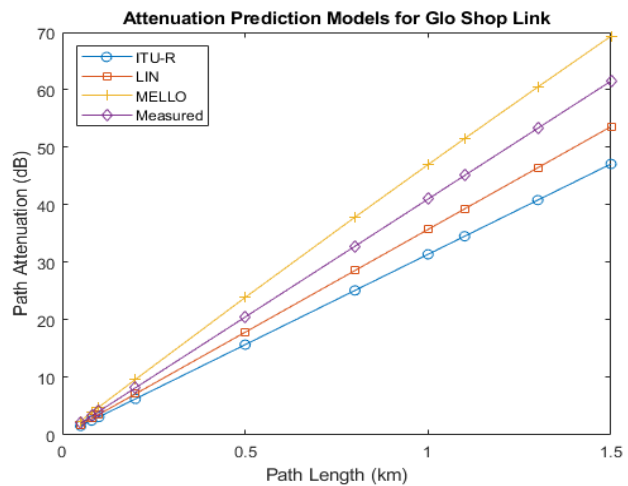

Fig. 6: Path Attenuation vs. Path length for GLO Shop

In Figure 7, the measured rainfall rate versus percentage of time exceeded for Lagos Island is presented. At $0.01 \%$ of the time exceeded, the rain rate is $256 \mathrm{~mm} / \mathrm{hr}$. Rain rate of Tarzan Yard link at same percentage of time is 287.32 $\mathrm{mm} / \mathrm{hr}$ (see Table 1), showing that the link value is greater than the measured value. This variance may be attributed to non-homogeneity of rainfall distribution in time and space and the distance between link and rain gauge which is located at the Lagos Island weather station, at a distance of about $3.9 \mathrm{~km}$.

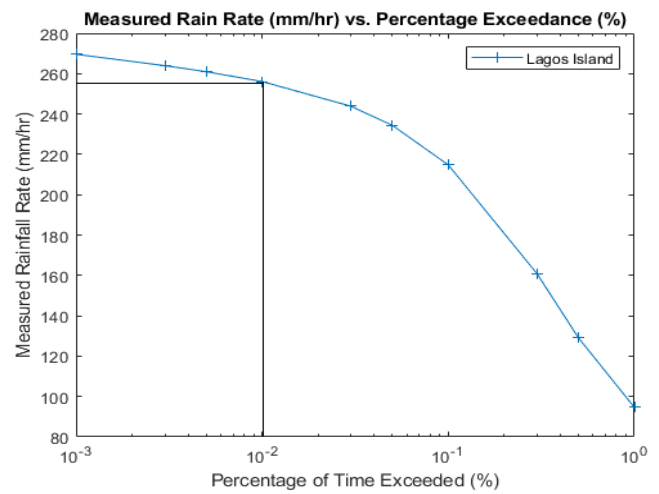

Fig. 7: Measured rainfall rate vs. Percentage of time exceeded for Lagos Island

Figure 8 compared path attenuation over varying path lengths for the three links. It is observed that the GLO Shop, Victoria Island Link has the lowest attenuation values, which is attributable to it having the shortest path length $(1.11 \mathrm{~km})$ of the three links. Both Tarzan Yard (1.19 $\mathrm{km})$ and Kofo Abayomi $(1.46 \mathrm{~km})$ links have higher path attenuation values.

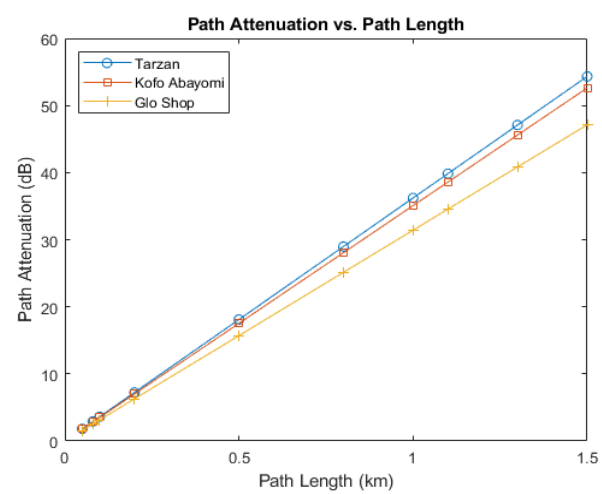

Fig. 8: Path attenuation vs. Path length at $18 \mathrm{GHz}$

Again, as shown in Figure, GLO Shop link exhibited the lowest attenuation values for percentages of time exceeded. Although, all three links have similar attenuation patterns, especially between 0.1 and $1.0 \%$ of time exceedance, the estimated attenuation values were all below measured values. At $0.01 \%$ of time exceeded, NIMET measurement is higher (at $48.2 \mathrm{~dB}$ ) than that of Tarzan Yard, Kofo Abayomi and GLO shop (43.1, 46.3 and $37.0 \mathrm{~dB}$ respectively).

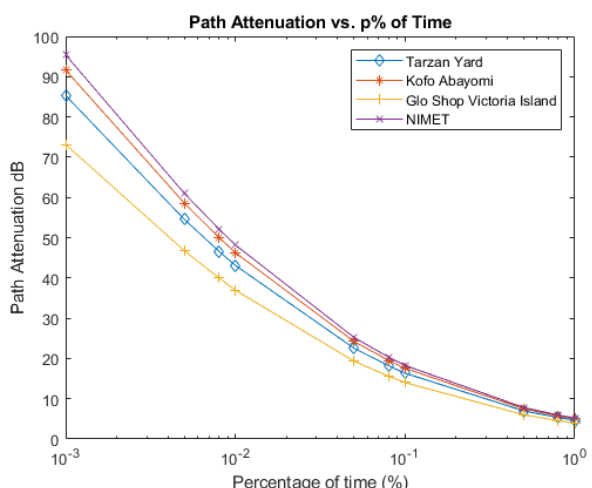

Fig. 9: Path attenuation vs. Percentage of time exceeded at $18 \mathrm{GHz}$

\section{Conclusion}

The performances of some rain attenuation prediction models at some GSM network locations in Lagos, Nigeria, using remote sensing at $\mathrm{Ku}$ band were investigated in this work. Three existing terrestrial rain attenuation prediction models (ITU-R P.530-17, Lin and Silva Mello models) were applied to three MW links at the same operating frequency of $18 \mathrm{GHz}$, and within the same locality at Victoria Island, Lagos. Locally sourced rain data were obtained from both NIMET and GLO. From the results obtained showed that the ITU-R P. 530-17 model presented the lowest attenuation prediction values for only one of the three sites (GLO shop, Victoria Island), while overestimating for the other two sites (Tarzan Yard and Kofo Abayomi).

For the three sites under study, the Silva Mello rain attenuation prediction model was the closest to measured values especially at short path lengths and it is therefore the most suitable terrestrial rain attenuation prediction for tropical Lagos. With longer path lengths, however, divergence from measured values was observed to be on the increase. The difference observed between measured 
and predicted attenuation for the three links can be attributed to the physical distances (about $4 \mathrm{~km}$ on the average) between the weather station and the various links being analyzed. The results from this study illustrate that attenuation prediction models can closely estimate path attenuation values along MW links in tropical regions and can thereby provide useful information for mobile telecommunication systems designer in ensuring link availability. Improved results can be realized by obtaining measurements from more closely arranged rain gauges to the links or rain gauges that are directly mounted at links under consideration.

\section{REFERENCES}

Akinyemi, G. A., Falade, J. A. and Kolawole, L. B. (2018). Estimation of rain attenuation at microwave bands in Nigeria, Journal of Radio Electronics, ISSN 1684-1719, No. 8 DOI:10.30898/16841719.2018.8.18

Ali, K. A. (2010). Remote Sensing. Laser Branch Department of Applied Sciences, University of Technology, Republic of Iraq, Ministry of Higher Education and Scientific Research.

Atlas, D. and Ulbrich, C. W. (1977). Path and Area integrated Rainfall Measurement ny MW Attenuation in 1-3cm Band. Journal of Applied Meteorology, Vol. 16, Issue 12, 1322-1331.

Barrett, E. C. (1983). Hydrological Application of remote sensing and remote data transmission; IAHS Publication No. 145, pp. 247-258.

Busari, H. O. and Fakolujo, O. A. (2021). Estimation of Attenuation due to Rain within $\mathrm{Ka}$ and $\mathrm{Ku}$ Bands in Oyo State, Nigeria FUOYE Journal of Engineering and Technology (FUOYEJET), Volume 6, Issue 1. http://dx.doi.org/10.46792/fuoyejet.v6i1.596

Chebil, J. and Rahman, T. A. (1999a). Development of 1 min rain rate contour maps for microwave applications in Malaysian Peninsula. Institution of Engineering and Technology Electronics Letters, Vol. 35 No.20, 1772-1774. DOI: 10.1049/e1:19991188

Chebil, J. and Rahman, T. A. (1999b). Rain rate statistical conversion for the prediction of rain attenuation in Malaysia. Institution of Engineering and Technology Electronics Letters, Vol. 35 No. 12, 10191021. DOI: $10.1049 / \mathrm{E} 1: 19990685$

Chwala, C. and Kuntsman. H. C. (2019). Commercial microwave link networks for rainfall observation: Assessment of the current status and future challenges. WIREs Water. 2019; Volume 6: Issue 2, E1337, 20 pages. https://doi.org/10.1002/wat2.1337

Crane, R. K. (1996). Electromagnetic Wave Propagation Through Rain. New York: Wiley ISBN: 978-0-471-61376-3.

Doumounia, A., Gosset, M., Cazenave, F., Kacou, M., \& Zougmore, F. (2014). Rainfall monitoring based on microwave links from cellular telecommunication networks: First results from a West African test bed. Vol. 41, Issue 16, p.6016-6022. https://doi.org/10.1002/2014GL060724

Ericson. (2019). Mobility Report/Mobile Subscriptions Q3-2019. Retrieved from https://www.ericsson.com/en/mobilityreport/reports/november-2019/mobile-subscriptions-q3-2019

Hossain, S. (2014). Rain Attenuation Prediction for Terrestrial Microwave Link in Bangladesh. Journal of Electrical and Electronics Engineering, Volume 7, Number 1, May 2014, 63-68

Kim, M. and Byung, H. K. (2018). Rainfall Detection and Rainfall Estimation Using Microwave Attenuation. MDPI, Artmosphere, Vol. 9, Issue 8, 1-21. https://doi.org/10.3390/atmos9080287

Leijnse, H., Uijlenhoet, R. and Srickter, J. N. M. (2007). Rainfall measurement using radio links from cellular communication networks. Water Resour. Res., vol.43, Issue 3, W03201, https://doi.org/doi:10.1029/2006WR005631

Lin, S. H. (1997). "11 GHz radio: Nationwide long term rain rate statistics and empirical calculation of $11 \mathrm{GHz}$ microwave rain attenuation," in The Bell System Technical Journal, vol. 56, no. 9, pp. 1581-1604, November 1977, doi: 10.1002/j.15387305.1977.tb00582.x..

Mandeep, J. S., Hassan, S. I. S., Ain, M. F. (2008). Rain rate conversion for various integration time for equatorial and tropical climates. International Journal of Satellite Communications and Networking, Vol. 26(No. 4), 329-345. Retrieved from https://doi.org/10.1002/sat.918

Mello, L. da Silva and Pontes, M. S. (2012). Unified Method for the prediction of rain attenuation in satellite and terrestrial link. Journal of Microwaves, Optoelectronics and Electromagnetic Applications, vol.11 no.1. p.1-14. DOI:10.1590/S217910742012000100001

Moupfounma, F., \& Martin, L. (1995). Modelling of the Rainfall Rate Cumulative Distribution for the Design of Satellite and Terrestrial Communication Systems. International Journal of Satellite Communications, 13(2), 105-115.

ITU-R P.530-17 (2017). Recommendation on Propagation data and prediction methods required for the design of terrestrial line-of-sight systems, P Series Radiowave Propagation)

Shaw, G. A. and Burke, H. K., (2003). Spectral Imaging for Remote Sensing; Lincoln Laboratory Journal, Vol .14, No. 1, pp. 3-28.

Siddique, U., Ahmad, L. and Raja, G. (2011). "Microwave Attenuation and Prediction of Rain Outage for Wireless Networks in Pakistan' s Tropical Region",International Journal of Microwave Science and Technology, vol. 2011, Article ID 714927, 6 pages, 2011. https://doi:10.1155/2011/714927

Shrestha, S., \& Choi, D. (2017a). Characterization of Rain Specific Attenuation and Frequency Scaling Method for Satellite Communication in South Korea, International Journal of Antennas and Propagation, Volume 2017, Article ID 8694748, 16 pages. https://doi.org/10.1155/2017/86947482017.

Shrestha, S., \& Choi, D. Y. (2017b). Rain attenuation over terrestrial microwave links in South Korea. IET Microwaves, Antennas and Propagation, 11(7), 1031-1039. https://doi.org/10.1049/ietmap.2016.0553

Teeuw, R., Whiteside, M., McWilliam, N., Zukowskyj, P., Hourigan, D., Mount, N. \& Jonathan, R. (2005). Field Techniques: GIS, GPS and Remote Sensing (p.67). Published by Geography Outdoors, Royal Geographical Society (with IBG), London.www.rgs.org/go ISBN 978-0-907649-88-5

Uijlenhoet R, Steiner, M, and Smith, J.A. (2003). Variability of Raindrop Size Distributions in a Squall Line and Implications for Radar Rainfall Estimation. Vol 4, No. 1, 43-61. DOI:https//:doi.org/10.1175/15257541(2003)004<0043:VORSDI>2.0.CO;2

Uijlenhoet, R., Overeem, A. and Leijnse, H. (2018). Opportunistic remote sensing of rainfall using microwave links from cellular communication networks. WIREs Water; 5:e1289. https://doi.org/10.1002/wat2.1289

Weng, Q. (2013) Introduction to Remote Sensing Systems, Data and Applications. Remote Sensing of Natural Resources, pp. 3-20. DOI: $10.1201 / b 15159-3$

Yussuff, A. I. O. and Khamis, N. H., (2013). Rain Height and Surface Temperature Variations for Nigeria, International Journal for Scientific and Engineering Research ,Vol. 4, no. 10, 791-794. 